\title{
Penerapan Metode Simple Additive Weighting (SAW) pada Sistem Pendukung Keputusan Pemilihan Lokasi untuk Cabang Baru Toko Pakan UD. Indo Multi Fish
}

\author{
${ }^{1}$ Nalsa Cintya Resti \\ ${ }^{1}$ Sistem Informasi, Universitas Nusantara PGRI Kediri \\ ${ }^{1}$ Kediri, Indonesia \\ E-mail: ${ }^{1}$ nalsacintyaresti@gmail.com
}

Abstract-Terdapat beberapa cara yang digunakan oleh sebuah perusahaan / toko untuk mengembangkan bisnisnya. Salah satu yang dapat dilakukan adalah dengan membuka cabang baru ditempat lain. Pemilihan daerah yang akan dijadikan cabang baru juga tidak dapat dipilih secara sembarangan. Terdapat kriteria-kriteria yang dapat meningkatkan laba perusahaan, dalam hal ini UD Indo Multi Fish. Dengan menggunakan metode Simple Additive Weighting (SAW) dapat memberikan rekomendasi daerah mana yang sesuai untuk dijadikan cabang baru toko tersebut. Nilai dengan ranking tertinggi merupakan daerah yang dapat rekomendasikan untuk dibuka cabang baru.

Keywords—Sistem Pendukung Keputusan, Rekomendasi, Simple Additive Weighting

\section{PENDAHULUAN}

Selain mengelola sumber daya manusia, salah satu upaya yang dilakukan oleh sebuah perusahaan agar usahanya semakin berkembang adalah dengan membuka cabang usaha baru yang memiliki prospek bisnis bagus. UD. Indo Multi Fish merupakan sebuah toko pakan ikan berskala sedang yang berada di desa Kepatihan Kabupaten Tulungagung. Toko tersebut ingin membuka cabang baru di tempat yang lain agar konsumen tidak harus membeli produk di toko utama. Selain itu agar bisnis toko Indo Multi Fish semakin berkembang di daerah lain. Terdapat alternatif pilihan lokasi yang dapat dipilih untuk dijadikan lokasi cabang baru, yaitu: daerah Gondosuli, daerah Sumbergempol, daerah Karangrejo, daerah Rejotangan, dan daerah Ngunut yang semuanya berada di Kabupaten Tulungagung.

Fuzzy Multiple Attribute Decision Making (FMADM) merupakan suatu metode yang digunakan untuk mencari alternatif optimal dari sejumlah alternatif dengan beberapa kriteria tertentu. Metode ini merupakan metode yang menentukan nilai bobot untuk setiap atribut, kemudian dilanjutkan dengan proses perankingan yang akan menyeleksi alternatif yang telah diberikan. Pada dasarnya, ada 3 pendekatan untuk mencari nilai bobot atribut, yaitu pendekatan subyektif, pendekatan obyektif, dan pendekatan integrasi antara subyektif dan obyektif. (Kusumadewi, 2007).

Permasalahan pemilihan cabang baru untuk toko Indo Multi Fish merupakan permasalahan dari Fuzzy Multiple Atribut Decision Making karena dalam mencari solusi menggunakan beberapa 
alternatif dan beberapa kriteria. Ada beberapa metode yang dapat digunakan untuk menyelesaikan masalah FMADM, yaitu salah satunya adalah metode Simple Additive Weighting (SAW). Metode SAW juga sering dikenal istilah metode penjumlahan terbobot karena dalam perhitungannya memperhitungkan bobot pada kriteria yang digunakan. Konsep dasar metode ini adalah mencari penjumlahan terbobot dari rating kinerja pada setiap alternatif pada semua atribut (Fishburn, 1967).

Penelitian ini bertujuan untuk mencari lokasi terbaik yang digunakan untuk pembangunan cabang baru di toko UD. Indo Multi fish. Metode yang digunakan dalam metode ini adalah metoe SAW yang dapat mengambil keputusan dengan efektif atas persoalan yang kompleks. Dengan adanya sistem pendukung keputusan pemilihan lokasi cabang baru diharapkan dapat membantu toko Indo Multi Fish mengembangkan bisnisnya.

\section{METODE PENELITIAN}

\subsection{Sistem Pendukung Keputusan}

Menurut Mann dan Watson, sistem pendukung keputusan merupakan sistem yang interaktif, membantu pengambilan keputusan melalui penggunaan data dan model-model keputusan untuk memecahkan masalah yang bersifat semi terstruktur dan tidak terstruktur. Menurut Maryam Alavi dan H. Albert Napier, sistem penunjang keputusan merupakan suatu kumpulan prosedur pemrosesan data dan informasi yang berorientasi pada penggunaan model untuk menghasilkan berbagai jawaban yang dapat membantu manajemen dalam pengambilan keputusan. Sedangkan menurut Litle, sistem penunjang keputusan merupakan suatu sistem informasi berbasis komputer yang menghasilkan berbagai alternatif keputusan untuk membantu manajemen dalam menangani berbagai permasalahan yang terstruktur ataupun tidak terstruktur dengan menggunakan data dan model.

\subsection{Fuzzy MADM}

Multi Attribute Decision Making merupakan suatu metode penunjang pengambilan keputusan yang Multiple Criteria Decision Making (MCDM) yang digunakan untuk memecahkan permasalahan dalam ruang diskrit. Pada dasarnya proses MADM dapat dilakukan melalui beberapa tahap, diantaranya penyusunan komponen kondisi, analisa serta sintesis sistem informasi.

Ada beberapa metode yang dapat digunakan untuk menyelesaikan masalah fuzzy MADM antara lain:
a. Simple Additive Weighting (SAW)
b. Analitical Hyrarchy Process (AHP)
c. Technique For Order Preference By Similarity To Ideal Solution (TOPSIS)
d. Weighting Product (WP)
e. ELECTRE 


\subsection{Metode SAW}

Konsep dasar metode Simple Additive Weighting adalah mencari penjumlahan terbobot dari rating kinerja pada setiap alternatif pada semua atribut (Fishburn, 1967) (MacCrimmon, 1968).

Metode ini membutuhkan proses normalisasi matriks keputusan ( ) kedalam skala yang dapat diperbandingkan dengan semua rating alternatif yang ada. Skor total untuk alternatif diperoleh dengan menjumlahkan seluruh hasil perkalian antara rating dan bobot tiap atribut.

2.4Langkah penyelesaian metode SAW

a. Menentukan kriteria yang akan dijadikan acuan dalam pengambilan keputusan, yaitu

b. Menentukan rating kecocokan setiap alternatif pada setiap kriteria

c. Membuat matriks keputusan berdasarkan kriteria , kemudian melakukan normalisasi matriks berdasarkan persamaan persamaan yang disesuaikan dengan jenis atribut (atribut keuntungan atau atribut biaya).

d. Membuat matriks normalisasi

e. Proses perankingan

2.5 Formula yang digunakan

a. Formula untuk melakukan normalisasi

$$
=\left\{\begin{array}{l}
\frac{x_{i j}}{\operatorname{Max} x_{i j}}, \\
\frac{\operatorname{Min} x_{i j}}{x_{i j}},
\end{array}\right.
$$

Dimana:

$$
\begin{aligned}
& =\text { Rating kinerja ternormalisasi } \\
& =\text { nilai maksimum dari setiap baris dan kolom } \\
& =\text { nilai minimum dari setiap baris dan kolom } \\
& =\text { baris dan kolomdari matriks } \\
& =1,2,3 \ldots \mathrm{m} \\
& =1,2,3 \ldots \mathrm{n}
\end{aligned}
$$

b. Formula untuk menghitung nilai preferensi

Nilai preferensi untuk setiap alternatif diberikan sebagai:

$$
v_{i}=\sum_{j=1}^{n} w_{j} r_{i j}
$$

Dimana:

$$
\begin{aligned}
& =\text { nilai akhir dari alternatif } \\
& =\text { bobot yang telah ditentukan }
\end{aligned}
$$


=normalisasi matriks

\section{HASIL PENELITIAN DAN PEMBAHASAN}

Tujuan dari penelitian ini adalah untuk memilih lokasi yang digunakan untuk pembangunan cabang baru UD. Indo Multi Fish. Terdapat lima daerah baru yang rencananya akan dipilh, yang merupakan alternatif pada penelitian ini, yaitu:

$A_{1}=$ daerah Gondosuli,

$A_{2}=$ daerah Sumbergempol,

$A_{3}=$ daerah Karangrejo,

$A_{4}=$ daerah Rejotangan,

$A_{5}=$ daerah Ngunut.

Adapun kriteria yang digunakan adalah:

$C_{1}=$ harga tanah untuk lokasi (juta rupiah)

$C_{2}=$ jarak dengan toko lama $(\mathrm{km})$

$C_{3}=$ jarak dengan gudang penyimpanan $(\mathrm{km})$

$C_{4}=$ tingkat persaingan dengan toko lain

$C_{5}=$ nilai investasi 3 tahun kedepan (\%)

$C_{6}=$ tingkat masyarakat yang memelihara ikan

Kriteria $C_{1}$ merupakan kriteria biaya, sehingga kriteria $C_{2}, C_{3}, C_{4}, C_{5}, C_{6}$ merupakan kriteria keuntungan. Bobot pengambilan keputusan dalam penelitian ini adalah:

$$
C_{1}=25 \% ; C_{2}=20 \% ; C_{3}=10 \% ; C_{4}=15 \% ; C_{5}=15 \% ; C_{6}=15 \%
$$

Skala ordinal untuk tingkat persaingan dengan

$$
\begin{gathered}
\text { toko lain ( } \\
\text { 1: rendah } \\
\text { 2: cukup } \\
\text { 3: sedang } \\
\text { 4: tinggi }
\end{gathered}
$$

5: sangat tinggi
Skala ordinal untuk tingkat masyarakat yang

$$
\begin{gathered}
\text { memelihara ikan ( : } \\
\text { 1: sangat jarang } \\
\text { 2: jarang } \\
\text { 3: cukup } \\
\text { 4: banyak }
\end{gathered}
$$

5: sangat banyak

3.1 Tabel kecocokan untuk alternatif dan kriteria

Dibawah ini merupakan tabel kecocokan untuk alternatif dan kriteria. Terdapat 6 kriteria dan 5 alternatif yang semua nilainya sudah ditampilkan dalam tabel 1. 
Tabel 1. NILAI KECOCOKAN UNTUK KRITERIA DAN ALTERNATIF

\begin{tabular}{|c|c|c|c|c|c|c|}
\hline \multirow{2}{*}{ Alternatif } & \multicolumn{7}{|c|}{ Kriteria } \\
\cline { 2 - 7 } & $\boldsymbol{C}_{\mathbf{1}}$ & $\boldsymbol{C}_{\mathbf{2}}$ & $\boldsymbol{C}_{\mathbf{3}}$ & $\boldsymbol{C}_{\mathbf{4}}$ & $\boldsymbol{C}_{\mathbf{5}}$ & $\boldsymbol{C}_{\mathbf{6}}$ \\
\hline Gondosuli & 50 & 9 & 10 & 5 & 75 & 5 \\
\hline Sumbergempol & 47 & 4 & 5 & 4 & 65 & 4 \\
\hline Karangrejo & 42 & 10 & 9 & 4 & 60 & 2 \\
\hline Rejotangan & 40 & 9 & 10 & 3 & 50 & 3 \\
\hline Ngunut & 52 & 6 & 7 & 4 & 100 & 3 \\
\hline
\end{tabular}

3.2 Hasil matriks normalisasi

Setelah mendapatkan nilai kecocokan untuk masing-masing alternatif dan kriteria, langkah selanjutnya adalah dengan mencari matriks normasisasi. Formula untuk mencari matriks normalisasi terdapat pada persamaan (1). Dikarenakan kriteria merupakan atribut biaya maka formula yang digunakan yaitu persamaan (1.2). sedangkan kriteria merupakan atribut keuntungan maka formula yang digunakan yaitu persamaan (1.1)

Hasil matriks normalisasi:

$$
R=\left[\begin{array}{cccccc}
0,8 & 0,9 & 1 & 1 & 0,75 & 1 \\
0,85 & 0,4 & 0,5 & 0,8 & 0,65 & 0,8 \\
0,95 & 1 & 0,9 & 0,8 & 0,6 & 0,4 \\
1 & 0,9 & 1 & 0,6 & 0,5 & 0,6 \\
0,77 & 0,9 & 0,7 & 0,8 & 1 & 0,6
\end{array}\right]
$$

3.3 Bobot pengambilan keputusan $\left(w_{i j}\right)$

Setelah mendapatkan matriks normalisasi, langkah selanjutnya adalah menentukan bobot pengambilan keputusan. Bobot pengambilan keputusan dalam penelitian ini adalah:

$$
C_{1}=25 \% ; C_{2}=20 \% ; C_{3}=10 \% ; C_{4}=15 \% ; C_{5}=15 \% ; C_{6}=15 \%
$$

\subsection{Proses perankingan}

Proses perankingan dalam tahap ini menggunakan formula pada persamaan (2). Perankingan didapat dari bobot pengambilan keputusan ( dikalikan dengan kolom pada matriks normalisasi ( . . Hasil perhitungan ditunjukkan dibawah ini.

Proses perankingan:

$$
\begin{gathered}
v_{1}=(0,8 \times 0,25)+(0,9 \times 0,2)+(1 \times 0,1)+(1 \times 0,15)+(0,75 \times 0,15)+(1 \times 0,15)=0,69 \\
v_{2}=(0,85 \times 0,25)+(0,4 \times 0,2)+(0,5 \times 0,1)+(0,8 \times 0,15)+(0,65 \times 0,15)+(0,8 \times 0,15)=0,68 \\
v_{a}=(0,95 \times 0,25)+(1 \times 0,2)+(0,9 \times 0,1)+(0,8 \times 0,15)+(0,6 \times 0,15)+(0,4 \times 0,15)=0,7975 \\
v_{4}=(1 \times 0,25)+(0,9 \times 0,2)+(1 \times 0,1)+(0,6 \times 0,15)+(0,5 \times 0,15)+(0,6 \times 0,15)=0,785 \\
v_{5}=(0,769 \times 0,25)+(0,9 \times 0,2)+(0,7 \times 0,1)+(0,8 \times 0,15)+(1 \times 0,15)+(0,6 \times 0,15)=0,80
\end{gathered}
$$


Dari perhitungan diatas dapat dilihat bahwa memiliki nilai yang paling tinggi dibandingkan yang lain. Hal tersebut berarti Alternatif merupakan alternatif yang memiliki ranking tertinggi.

\section{SIMPULAN DAN SARAN}

Dari perhitungan diatas dapat dilihat bahwa alternatif yaitu daerah Ngunut dapat dijadikan sebagai rekomendasi daerah untuk cabang baru toko UD Indo Multi Fish. Hal ini dikarenakan daerah Ngunut memiliki ranking tertinggi dalam perhitungan dibandingkan daerah yang lain.

Metode Simple Additive Weighting (SAW) dapat dijadikan sebagai suatu sistem pendukung keputusan suatu permasalahan yang terjadi, sehingga keputusan yang diambil dapat memberikan keuntungan maksimal kepada toko UD. Indo Multi Fish.

\section{DAfTAR Pustaka}

[1] Fishburn, P. C., A Problem-based selection of multi-attribute decision making methods, Blackwell Publishing, 1967.

[2] Kusrini, Konsep dan Aplikasi sistem Pendukung Keputusan. Yogyakarta: Andi, 2007.

[3] Kusumadewi, Sri and Purnomo H., Aplikasi logika fuzzy untuk pendukung keputusan, Yogyakarta: Graha Ilmu, 2007.

[4] MacCrimmon, K. R.,Decision Making among multiple atribute alternatives: a survey and consolidated approach, 1968. 